\title{
Effect of temperature on Temora longicornis swimming behaviour: illustration of seasonal effects in a temperate ecosystem
}

\author{
Maud Moison ${ }^{1,2,3,4, *}$, François G. Schmitt ${ }^{2,3,4}$, Sami Souissi ${ }^{2,3,4}$ \\ ${ }^{1}$ Leibniz Institut of Marine Sciences, IFM-GEOMAR, 24105 Kiel, Germany \\ ${ }^{2}$ Université Lille Nord de France, 59000 Lille, France \\ ${ }^{3}$ Université des Sciences et Technologies de Lille (USTL), Laboratoire d'Océanologie et de Géosciences (LOG), \\ 62930 Wimereux, France \\ ${ }^{4}$ Centre National de la Recherche Scientifique (CNRS), Unité Mixte de Recherche (UMR) 8187, 62930 Wimereux, France
}

\begin{abstract}
The present study investigated the effect of temperature on male and female swimming activity of the calanoid copepod Temora longicornis, sampled during winter (February) and summer (August) in the English Channel coastal ecosystem. Video recordings were conducted at 3 temperatures representative of those to which these organisms are normally exposed $(13,16$ and $20^{\circ} \mathrm{C}$ ) and one extreme-event temperature $\left(24^{\circ} \mathrm{C}\right)$. Examinations of instantaneous velocity and symbolic analysis (i.e. dynamics of swimming states discretized from time series of instantaneous velocity) showed that $T$. longicornis changed its behaviour when confronted with environmental temperature variations. Swimming speed increased as temperature increased. In warmer water, this copepod displayed higher swimming activity, break periods were less frequent, and the frequency of jumps increased. This phenomenon was amplified when the environmental temperature was increased to $24^{\circ} \mathrm{C}$. These observations revealed a considerable tolerance to high temperatures and an ability to adjust to environmental temperature changes. The 'summer population' was less active in the low temperature range, but the swimming speed reached a higher value at higher temperatures than that shown by the 'winter population'. The results of the present study highlighted changes in the individual behaviour of this copepod in response to changing seasonal conditions in the form of swimming activity, and thus its ability to maintain biological processes throughout the year, even in a restrictive environment.
\end{abstract}

KEY WORDS: Copepod - Swimming behaviour - Temperature effect - Seasonal variation · Temora longicornis $\cdot$ Symbolic dynamics

\section{INTRODUCTION}

Temperature affects all biological processes, from molecular to population scale, especially in poikilothermic marine invertebrates (Pörtner \& Farrell 2008), e.g. copepods (Kinne 1970, Mangum et al. 1972). The physical properties of cellular components, as well as biochemical reaction kinetics, are highly sensitive to temperature (Brown et al. 2004 and references therein), which appears as a key forcing in any life cycle trait. These traits include respiration (Gauld \& Raymont 1953, Ikeda et al. 2001), gen- eration time and stage-specific mortality (HalsbandLenk et al. 2002, Devreker et al. 2005) and the reproduction of and predation for poikilothermic organisms (Devreker et al. 2005, Holste et al. 2009).

In the marine pelagic ecosystem, copepods are subjected to highly variable and restricted conditions in a 3-dimensional diluted and patchy environment. Their ability to maintain constant life processes, i.e. maximize encounter rate with potential partners or prey and minimize predation risk, in spite of changing environmental conditions, is crucial for their fitness. Consequently, to face such a changing envi- 
ronment, copepods have developed a range of strategies, including a wide spectrum of swimming behaviour to search for food (Tiselius 1992, van Duren \& Videler 1995) and sexual partners (van Duren \& Videler 1996, Doall et al. 1998) and to avoid predators (van Duren \& Videler 1996, Tiselius et al. 1997). The patterns of zooplankton swimming behaviour may be affected by changing temperature conditions, i.e. either no change (Metridia longa, Hirche 1987; Calanus finmarchicus, Lenz et al. 2005), or a decrease (Acartia tonsa, and C. glacialis, Hirche 1987, Larsen et al. 2008) or a rise in swimming activity during warmer conditions (Lenz et al. 2005).

The effect of seasonal temperature variation on the swimming velocity of copepods, especially Temora longicornis, is not well known, although this variation may be important in the aquatic environment. With rising temperatures in the northern hemisphere (Levitus et al. 2000, 2005), there is a need to study behavioural observations in relation to variations in environmental temperature. This, in turn, will give us a better understanding of natural selection processes and their implications on larger-scale mechanisms such as spatial distribution (Beaugrand et al. 2002), demography and dynamic of the populations and communities (Clark et al. 2003, Molinero et al. 2008), as well as consequences for trophic interactions (Richardson \& Schoeman 2004, Frederiksen et al. 2006).

The calanoid copepod Temora longicornis is distributed throughout the North Atlantic Ocean (CPR Survey Team 2004) and is one of the major copepods (in terms of number and biomass contribution to the total zooplankton) in the English Channel (Williams et al. 1994, John et al. 2001), which is characterized by large seasonal fluctuations in the temperature of the surface water (from around $8^{\circ} \mathrm{C}$ in winter to about $20^{\circ} \mathrm{C}$ in summer). Although the population size of this copepod shows marked changes (Brylinski et al. 1988), it is present year round and dominates copepod assemblages during the spring bloom of phytoplankton (Quisthoudt et al. 1987, John et al. 2001). Consistent with its broad spatio-temporal distribution, this eurythermic species tolerates a wide range of temperature fluctuations. Thus, the life history traits (i.e. reproductive event and egg production as well as hatching, stage development and adult survival) take place in waters that range from a few degrees above $0^{\circ} \mathrm{C}$ to around 20 to $25^{\circ} \mathrm{C}$ (Halsband \& Hirche 2001, Halsband-Lenk et al. 2002, Devreker et al. 2005). Moreover, a macrotidal (i.e. highly dynamic system) coastal ecosystem such as the English Channel is characterized by the multiscale intermittent distribution and fluctuation of the temperature related to different forcings occurring at different time scales (from minutes to days) such as in tidal input, river flow fluctuations, meteorology and turbulence (Dur et al. 2007). In this context of high variability, the ability to adapt behaviour is crucial. According to Gill \& Crisp (1985), T. longicornis seems able to accommodate its swimming effort: the frequency of the limb movements increases as the temperature rises from 0 to $22.5^{\circ} \mathrm{C}$. Nevertheless, the sampling period may determine the size of the adaptive response of the rate of beating to sea temperature change: the 'summer population' is less active in the low temperature range than the 'winter population', but swimming reaches a higher rate at higher temperatures (Gill \& Crisp 1985).

The aim of the present study was to analyze the effect of temperature on the swimming velocity of different populations of Temora longicornis inhabiting markedly different environmental conditions. During summer, high temperature and food availability, as well as a larger copepod density, characterise the copepod's environment, which contrasts with winter environmental conditions, in which temperature is low and food availability and conspecific density are noticeably reduced. The approach used here consisted of video recording $T$. longicornis individuals at different temperatures. The individual swimming pathways were characterized both quantitatively (swimming speed) and qualitatively (symbolic dynamic analysis). Finally, the results are discussed in an ecological framework with regard to the fitness of populations facing changes in environmental conditions.

\section{MATERIAL AND METHODS}

\section{Sampling and acclimation}

The influence of temperature was studied on 2 dates, representing 2 seasonal periods: one on 31 August 2007 and the other on 26 February 2008. Plankton samples were taken by means of a plankton net (200 $\mu \mathrm{m}$ mesh size) from the eastern English Channel (coastal point: $1^{\circ} 31^{\prime} 17^{\prime \prime} \mathrm{E}, 50^{\circ} 40^{\prime} 75^{\prime \prime} \mathrm{N}$ ). The samples were immediately placed in a cooler box, diluted in 201 of seawater and returned to the laboratory. On each sampling date, surface seawater was also collected and filtered through Whatman $\mathrm{GF} / \mathrm{C}$ glass fiber filters $(0.7 \mu \mathrm{m})$ for further use in the laboratory during the behavioural experiments.

Viscosity is a major hydrodynamic force, especially important to very small objects, and its effects on swimming motion are related body size (Gill \& Crisp 
1985, Granata \& Dickey 1991). Therefore, to avoid biased results and obtain comparable and consistent data, adults of Temora longicornis were selected according to size (mean \pm SE of total length $=1.4 \pm$ $0.1 \mathrm{~mm}$ for males and females in August, and $1.4 \pm$ $0.1 \mathrm{~mm}$ for males and $1.2 \pm 0.3 \mathrm{~mm}$ for females in February).

Four life conditions were tested: 2 sea temperatures close to the environmental mean $\left(13\right.$ and $\left.16^{\circ} \mathrm{C}\right)$, the maximum sea temperature $\left(20^{\circ} \mathrm{C}\right)$ measured during the study period and an extreme sea temperature $\left(24^{\circ} \mathrm{C}\right)$. Both sexes of Temora longicornis adults were distributed among test beakers, each containing 11 of filtered seawater (Fig. 1). The organisms were then acclimatised for $30 \mathrm{~h}$, during which the temperature was gradually increased by an increment of $2^{\circ} \mathrm{C} \mathrm{h}^{-1}$ to the desired test value. This was kept constant for at least $22 \mathrm{~h}$. For the 2 lower temperatures (13 and $16^{\circ} \mathrm{C}$ ), each group of copepods was placed into a temperature-controlled chamber. For the 2 samples at 20 and $24^{\circ} \mathrm{C}$, temperatures were maintained using $25 \mathrm{~W}$ aquarium heaters.
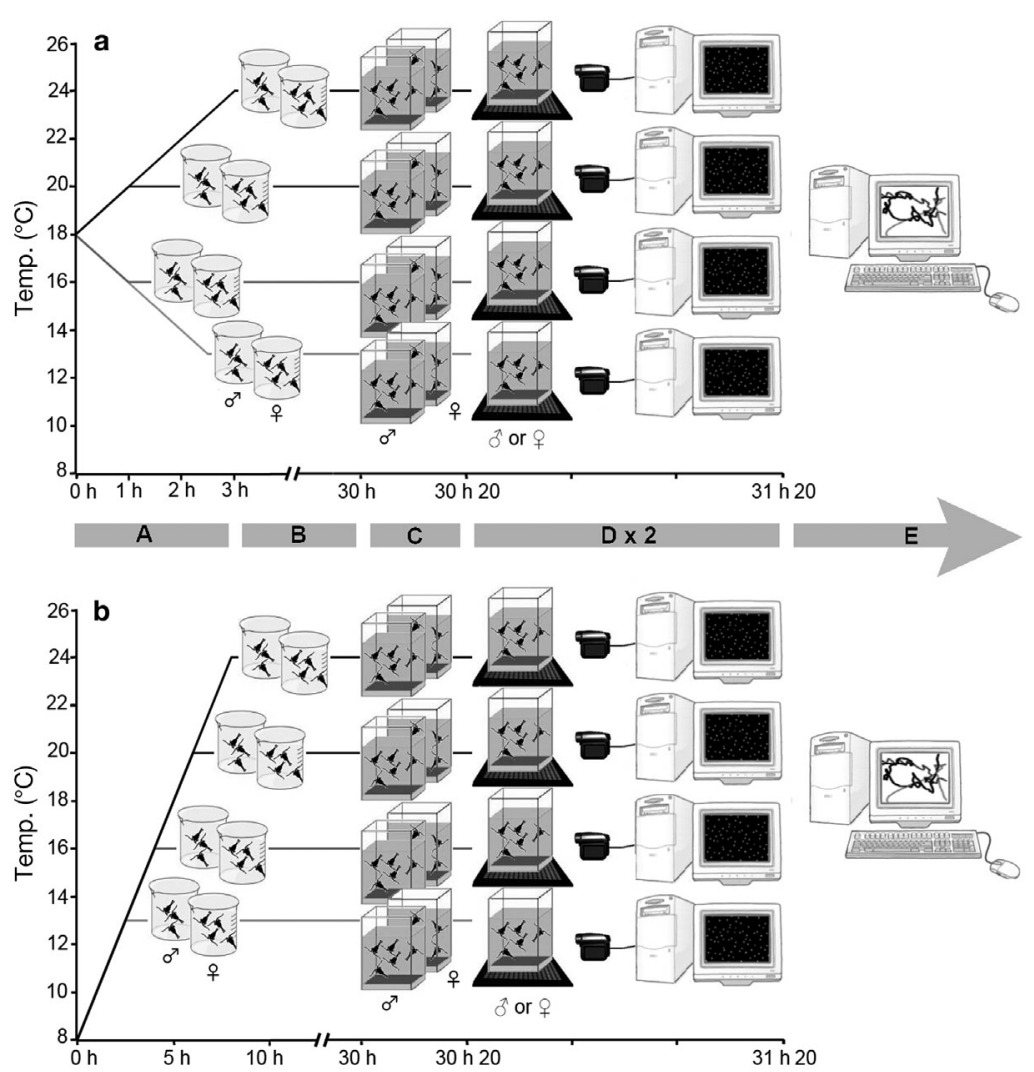

Fig. 1. Schematic drawing of the experimental setup for both experiments: (a) 31 August 2007 and (b) 26 February 2008. A: time to bring to the right temperature; B: period of acclimation at constant temperature; C: recovery from handling stress before video recording; D: video recording-performed twice, once for females and once for males - with infrared light and camera during the night; E: image analysis and coordinate extraction

\section{Video recording process}

The same recording protocol was executed during each experimental session. The video recording processes, which were performed during the night to coincide with biological rhythms (e.g. Temora longicornis is known to feed predominantly at night, Head et al. 1984), took place in a dark room to avoid phototactic behaviour of these organisms (Head et al. 1984). The copepods were separated by sex to avoid the potential influence of interactions between both sexes (Doall et al. 1998, Weissburg et al. 1998, Goetze \& Kiørboe 2008). At $20 \mathrm{~min}$ before the beginning of the recording, around 10 males or females were placed into an aquarium $(15 \times 15 \times 15 \mathrm{~cm})$ containing filtered seawater. This relatively important ratio of the number of individuals to the volume of water was chosen so that we could obtain long recording fragments of trajectories (i.e. a fragment without contact with other individuals or the walls). The duration of the recording was about $60 \mathrm{~min}$ under infrared light (880 nm light-emitting diode) using an infrared-sensitive camera (Sony DCR HC 96; temporal resolution: $40 \mathrm{~ms}$, spatial resolution: $720 \times 576$ pixels)

The horizontal and vertical coordinates were extracted frame by frame using the software Labtrack (Labtrack v.2.1, Bioras). Only trajectories longer than 2 s (50 data points) were kept to calculate statistically significant measurements. The numerical analysis was applied on an average of about 100 sequences for each condition (approximately 150000 data points per environmental condition) (Table 1).

\section{Data analysis}

\section{Analysis of trajectories}

First, the instantaneous velocity (Vi) was estimated for each time step. $X(n)$ was the 2-dimensional (2D) position of the copepod in the frame $n$, and $d_{i}=\| X(i)-X(i-$ 1)I, which is the distance between the position of the copepod at frame $i-1$ and the frame $i$. Vi is defined as:

$$
\mathrm{Vi}=\frac{d_{i}}{\tau}
$$

where $\tau$ is the time resolution. Mean and maximum values were considered for each experiment, together with their prob- 
Table 1. Temora longicornis. Experimental conditions and data collected for each video recording analyzed on $31 \mathrm{Au}-$ gust 2007 (summer, S) and 26 February 2008 (winter, W). In situ temperatures were $18.2^{\circ} \mathrm{C}$ and $7.8^{\circ} \mathrm{C}$ in the summer and winter, respectively. Information recorded included the number of specimens studied (n), the temperature of each experiment $\left(T_{\exp } \pm \mathrm{SD}\right)$, the number of trajectories extracted (no. of tracks) and the total number of data values analysed (no. of values)

\begin{tabular}{|c|c|c|c|c|}
\hline & $T_{\exp }\left({ }^{\circ} \mathrm{C}\right)$ & $\mathrm{n}$ & No. of tracks & No. of values \\
\hline \multicolumn{5}{|c|}{ Females } \\
\hline S_1 & $13.5 \pm 1$ & 10 & 228 & 392907 \\
\hline S_2 & $15.5 \pm 1$ & 10 & 141 & 238790 \\
\hline S_3 & $20.4 \pm 1$ & 10 & 55 & 72125 \\
\hline S_4 & $24.5 \pm 1$ & 10 & 156 & 287564 \\
\hline \multicolumn{5}{|c|}{ Males } \\
\hline S_1 & $13.5 \pm 1$ & 10 & 60 & 107506 \\
\hline S_2 & $15.9 \pm 1$ & 10 & 76 & 88596 \\
\hline S_3 & $20.9 \pm 1$ & 10 & 100 & 106972 \\
\hline S_4 & $24.6 \pm 1$ & 10 & 98 & 160983 \\
\hline \multicolumn{5}{|c|}{ Females } \\
\hline W_1 & $13 \pm 1$ & 10 & 117 & 193852 \\
\hline W_2 & $15.6 \pm 1$ & 10 & 123 & 236543 \\
\hline W_3 & $20 \pm 1$ & 8 & 20 & 33234 \\
\hline W_4 & $24.4 \pm 1$ & 7 & 23 & 14494 \\
\hline \multicolumn{5}{|c|}{ Males } \\
\hline W_1 & $13.2 \pm 1$ & 10 & 57 & 99345 \\
\hline W_2 & $15.8 \pm 1$ & 10 & 165 & 163743 \\
\hline W_3 & $20.2 \pm 1$ & 10 & 113 & 147820 \\
\hline W_4 & $24.4 \pm 1$ & 7 & 25 & 42161 \\
\hline
\end{tabular}

ability density function (pdf), to emphasize extreme event distribution.

Other analyses were performed to consider the dynamics of the copepods' swimming behaviour, for which the ordering of events was important. The first was the Fourier power spectral analysis. The energy spectrum $E(f)$ associated with frequency $f$ was estimated as the Fourier transformation of the autocorrelation function:

$$
E(f)=\frac{1}{\pi} \int_{0}^{\infty} \cos (f t) C(t) \mathrm{d} t
$$

where $C(t)$ is the autocorrelation function. For a 2D trajectory, the power spectrum of the path was estimated as the half-sum of the power spectrum of each coordinate as:

$$
E(f)=\frac{1}{2}\left((f)+E_{Y}(f)\right)
$$

The power spectrum was useful in identifying possible frequency peaks associated with periodic forcing, or in estimating scaling ranges where the power spectrum was fitted as:

$$
E(f)=K f^{-\beta}
$$

where $K$ is a constant and $\beta$ is the scaling exponent for the considered frequency range. If the copepod underwent a Brownian motion, $\beta=2$, and when Eq. (4) was verified with $\beta \neq 2$, the process might have belonged to scaling families such as Lévy motion or multifractal random walk (Schmitt \& Seuront 2001).

\section{Symbolic dynamics}

Symbolic dynamics is a method of studying and characterizing the complexity of discrete systems that possess a finite number of symbols. This approach has been well adapted to the study of animal behaviour, and especially that of copepods (Schmitt et al. 2006, Moison et al. 2009, Michalec et al. 2010). Each trajectory can be translated into sequences of successive discrete events; in the present study a swimming state was assigned to each frame based on the velocity information. Three states were chosen, with reference to instantaneous velocity: (1) 'break' (B) for zero velocity, corresponding to no appendage movement; (2) 'fast swimming' (F) corresponding to situations when the instantaneous displacement between 2 frames is larger than the body size of copepods: this corresponds to a threshold of $30 \mathrm{~mm} \mathrm{~s}^{-1}$; (3) 'slow swimming' (S) corresponding to when the velocity was smaller than the threshold, but positive, in which the behaviour was considered as a 'cruise'.

With this approach, the behaviour dynamics were reduced to a succession of symbols, one symbol for each frame. Behaviour was characterized by the percentage of total time spent in one state and the mean of residence time for each state (Moison et al. 2009, Dur et al. 2010, Michalec et al. 2010).

Taking into account the 3 states previously defined, one can extract the rhythm of the series and then perform several analyses. In our case, Shannon entropy analysis of differential swimming states was also used here to characterize the complexity in the dynamics. The Shannon entropy $(H)$ was defined as:

$$
H=-\sum \mathrm{p}\left(A_{i}\right) \log \mathrm{p}\left(A_{i}\right)
$$

where $\mathrm{p}\left(A_{i}\right)$ is the probability mass function of outcome symbol $A_{i}$. In Eq. (5) the logarithm used was base 2 .

The Shannon entropy analysis quantifies the information contained in the sequence of random variables. If the results are more frequent, then the uncertainty is lower and $H$ is also lower. In extreme cases, entropy is equal to 0 when the outcomes are entirely predictable. In our case, higher values could 
mean that the evolution of the swimming states was more chaotic and unpredictable. Conversely, a decrease in the value could mean that the degree of uncertainty decreased, highlighting the emergence of repeating units, and thus an adaptive behavioural pattern. $H$ can be used to express the predictability of change in a complex system and has been widely used in time series analysis (Ebeling 1997, Moison et al. 2009).

\section{Statistical testing}

Statistical comparisons were carried out using a non-parametric Mann-Whitney $U$-test with a significance level set at $p<0.05$ for (1) the same sex and the same season between each temperature condition, (2) the same sex and the same temperature between both seasons and (3) the same temperature and the same season between both sexes. Differences between mean and maximum swimming speed, mean $H$ and the results of symbolic dynamic analysis in all experimental conditions were quantified.

\section{RESULTS}

\section{Use of the term 'population'}

Life cycles of copepods are multigenerational. Each generation, from nauplii to mature adult, presents specific and distinct features (derived from abundance, biomass, body size and biotic potential; Halsband-Lenk et al. 2004, Devreker et al. 2005). Temora longicornis is present and breeds continuously throughout the year in the English Channel (Devreker et al. 2005). This species displays a cycle of 5 successive generations per year. However, several generations can overlap and coexist; thus, at a given time and place, sampled individuals may not be from the same generation. For this reason, we chose to call our samples 'winter population' and 'summer population' and not use the term 'generation', even if the 2 studied groups could not clearly belong to the same generation.

\section{Analysis of velocity}

Our results indicated changes in $\mathrm{Vi}$, common to both populations in both male and female Temora longicornis, linked to temperature variation (Fig. 2a,b).
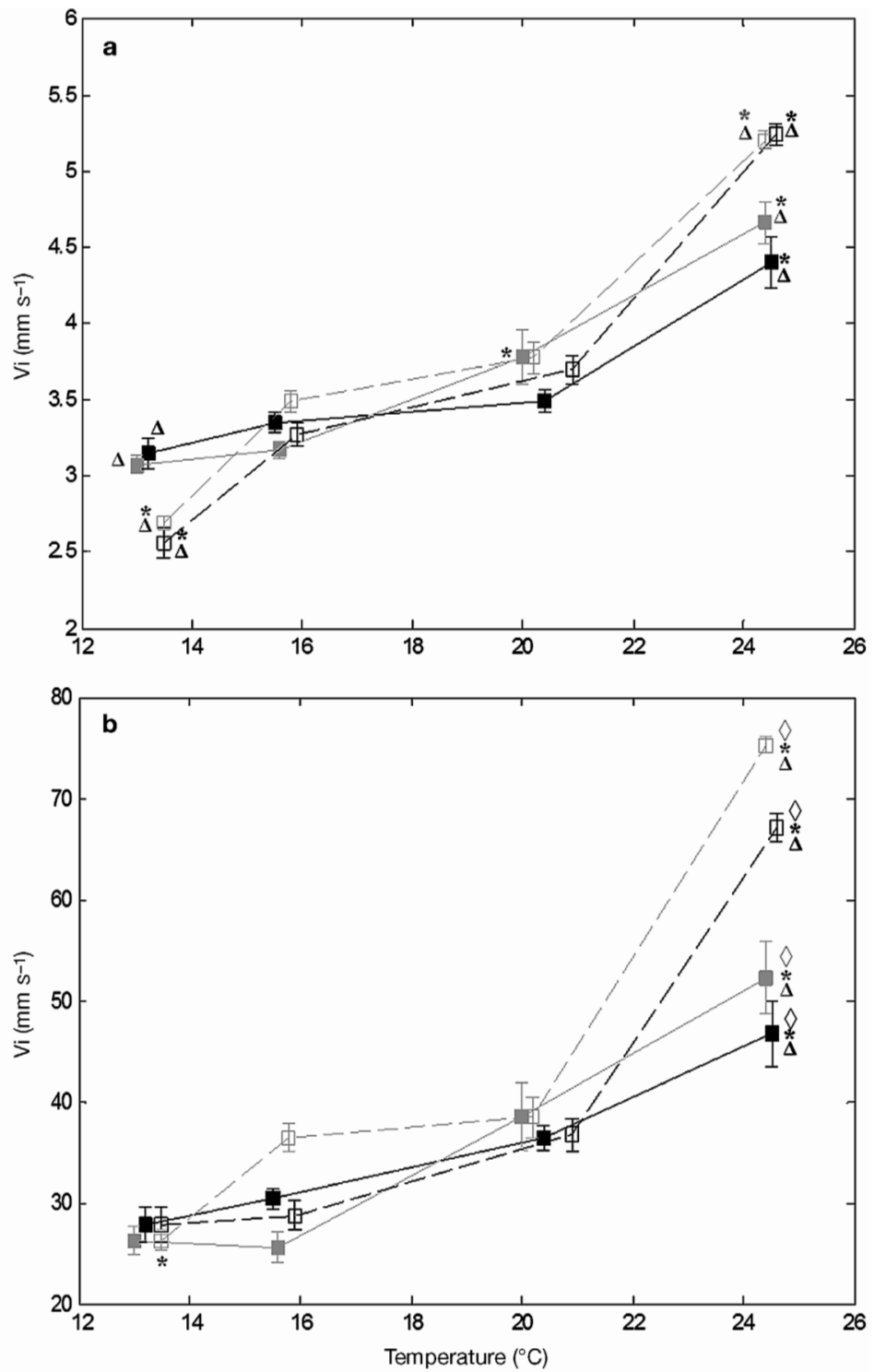

Fig. 2. Temora longicornis. (a) Average instantaneous velocity (Vi) and (b) maximum Vi (mean \pm confidence limits), averaged from trajectories extracted for each experiment (male; black line, female; grey line) on 31 August 2007 (dashed line) and 26 February 2008 (solid line). Significant differences were noted between temperature conditions for the same sex and the same season (*), between both seasons for the same sex and the same temperature $(\Delta)$ and between both sexes for the same temperature and the same season

$(\diamond)$ (Mann-Whitney $U$-test, $\alpha=5 \%$ )

The mean and maximum of $\mathrm{Vi}$ increased for both sexes with a rise in temperature. The mean swimming speed varied from around 3 to $5 \mathrm{~mm} \mathrm{~s}^{-1}$ (Fig. 2a) and maximum values reached were 2 -fold higher than the mean values (Fig. 2b). No distinctions were observed between male and female behaviour. Nevertheless, for both males and females, the values of the instanta- 
neous velocities averaged during the highest temperature were 1.5 and 2 times greater than those measured during the lowest temperature for both winter and summer, respectively. In addition, from the lowest temperature to the highest temperature, the maximum swimming speeds increased 2 -fold and 3 -fold for the winter and the summer population, respectively. Thus, winter population individuals swam faster at $13^{\circ} \mathrm{C}$, with an average speed of ca. $3.1 \mathrm{~mm}$ $\mathrm{s}^{-1}$, compared with those from the summer population (average speed, ca. $2.7 \mathrm{~mm} \mathrm{~s}^{-1}$ ). There was an inverse relationship at $24^{\circ} \mathrm{C}$, where the maximum speeds recorded in summer were higher $\left(75 \mathrm{~mm} \mathrm{~s}^{-1}\right.$ for females and $67 \mathrm{~mm} \mathrm{~s}^{-1}$ for males) than those observed in winter ( $52 \mathrm{~mm} \mathrm{~s}^{-1}$ for females and $48 \mathrm{~mm} \mathrm{~s}^{-1}$ for males).

These results were confirmed by the probability density analysis of instantaneous swim speed (Fig. 3). The experiments performed at intermediate temperatures $\left(16\right.$ and $\left.20^{\circ} \mathrm{C}\right)$ exhibited a very similar pdf. Experiments in cold conditions showed low probability densities for extreme high speed, which was especially true for those conducted in summer. Conversely, extreme values of swimming speed were more frequent, especially for experiments performed at warmer temperatures in summer.

Inherent velocity fluctuations in the swimming behaviour of Temora longicornis were measured by power spectral analysis. Each spectrum showed similar features for each temperature condition (Fig. 4). The spectra followed a power law when frequencies were below $1 \mathrm{~Hz}$ and a slightly flat pattern revealing a white noise for high frequencies. Power spectra density plots of swimming velocity also showed a marked difference for extreme temperatures (Fig. 4). For temperatures from 13 to $20^{\circ} \mathrm{C}$, the slopes of power spectra law regression for each population and both sexes were similar and were about $0.4 \pm 0.2 \mathrm{SD}$ (Table 2). In warmer conditions, the values of slopes were much higher than 0.6, especially during the summer period when the energy spectra exhibited a much steeper incline, which was followed by a change of regime, with a flatter slope from frequencies around $0.1 \mathrm{~Hz}$.

The value of $H$ was relatively high for all different populations and experimental conditions and was greater than 0.55 (Table 3 ). $H$ increases with a rise of temperature, indicating a growing variability of the symbols sequences dynamics (i.e. succession of time-sequenced states). Such a pattern constitutes an increasing complexity of the swimming activity in the presence of elevated temperature. However, this indicator does not reflect a clear difference between the sexes or between populations.

Temperature is the main factor determining viscosity. Viscosity tends to fall as temperature rises. Thus, variations of temperature could have affected the ability of Temora longicornis to sink. In warmer conditions, organisms may have more pronounced sinking behaviour, which could be confused with activity. In order to avoid this potential bias, hypothetical sinking time was considered (Fig. 5) and defined as the periods when the copepod moved
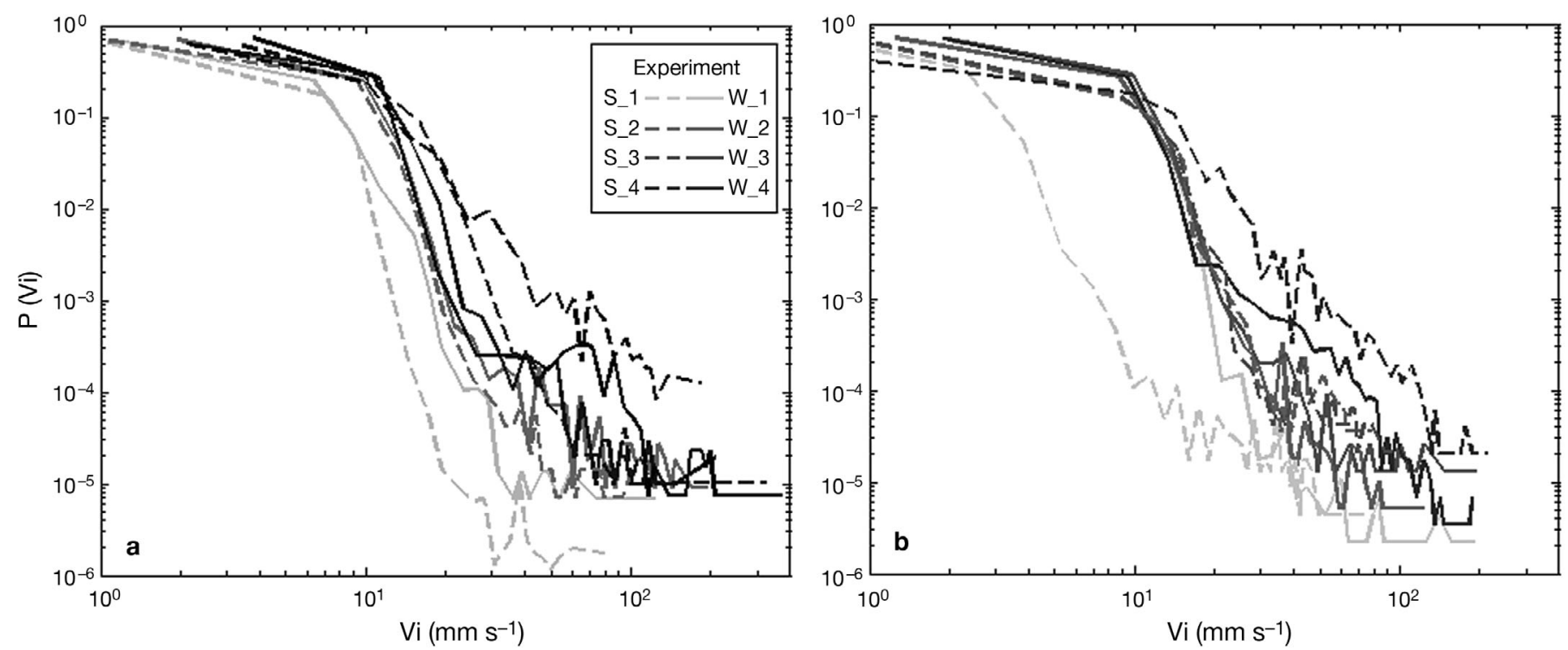

Fig. 3. Temora longicornis. Probability density functions, P(Vi), (log/log plot) of the instantaneous velocities (Vi) calculated from the trajectories extracted for each experiment: 26 February 2008 (winter, W, solid line) and 31 August 2007 (summer, S, dashed line), at ca. $13^{\circ} \mathrm{C}(1), 16^{\circ} \mathrm{C}(2), 20^{\circ} \mathrm{C}(3)$ and $24^{\circ} \mathrm{C}(4)$, for (a) males and (b) females 

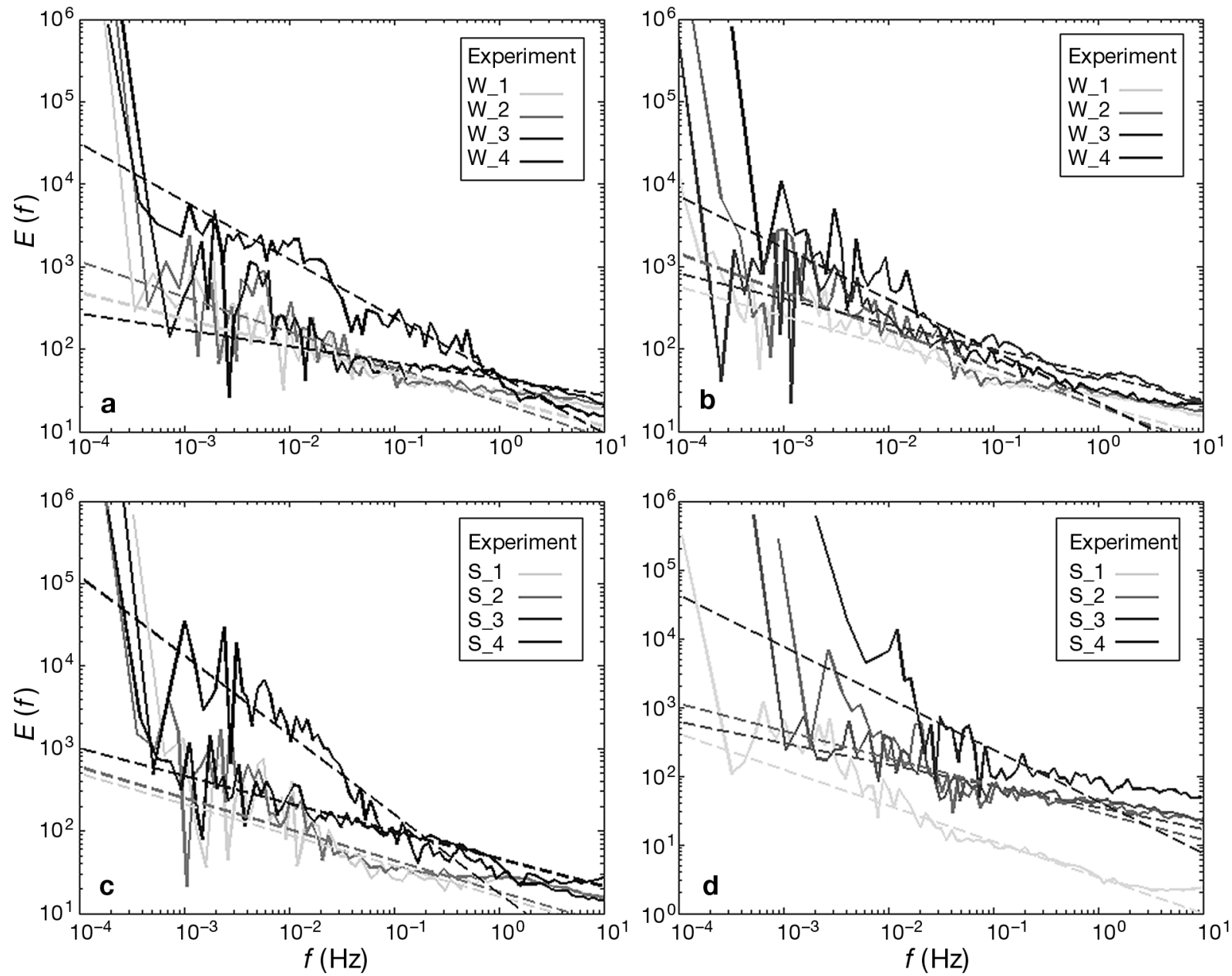

Fig. 4. Temora longicornis. Energy spectrum (E(f), Eq. (3), (log/log)) of instantaneous velocity frequencies, $f(\mathrm{~Hz})$, calculated from the trajectories extracted for each experiment at ca. $13^{\circ} \mathrm{C}(1), 16^{\circ} \mathrm{C}(2), 20^{\circ} \mathrm{C}(3)$ and $24^{\circ} \mathrm{C}(4)$, for $(\mathrm{a}, \mathrm{c}) \mathrm{males}$ and $(\mathrm{b}, \mathrm{d})$ females, for 2 experiments, (a,b) 26 February 2008 and (c,d) 31 August 2007 and their power-law regressions (dotted lines)

toward the bottom, perpendicular to itself, with a speed equal to or less than $3 \mathrm{~mm} \mathrm{~s}^{-1}$ (the theoretical top sinking speed for this species; Tiselius \& Jonsson 1990). With an overall coverage value between 11 and $17 \%$, there was no significant effect of temperature on the hypothetical state (Mann-Whitney $U$-test).

Table 2. Temora longicornis. Value of exponents $(\beta)$ derived from power law regressions (Eq. 4) of each energy spectrum for experiments at $13^{\circ} \mathrm{C}(1), 16^{\circ} \mathrm{C}(2), 20^{\circ} \mathrm{C}(3)$ and $24^{\circ} \mathrm{C}(4)$ on 31 August 2007 (summer) and 26 February 2008 (winter)

\begin{tabular}{|c|c|c|c|c|c|c|c|c|}
\hline & \multicolumn{4}{|c|}{ - Female- } & \multicolumn{4}{|c|}{-Male } \\
\hline & 1 & 2 & 3 & 4 & 1 & 2 & 3 & 4 \\
\hline Summer & -0.5 & -0.4 & -0.3 & -0.75 & -0.4 & -0.4 & -0.4 & -0.7 \\
\hline Winter & -0.35 & -0.4 & -0.4 & -0.6 & -0.3 & -0.4 & -0.4 & -0.75 \\
\hline
\end{tabular}

For all temperatures tested, Temora longicornis adopted the usual and expected patterns of swimming behaviour. Breaks dominated the behaviour pattern, a great proportion of time was spent in slow swimming (from 29 to $48 \%$ of total time, depending on sex and condition) and rapid movements rarely occurred $(<1 \%$ of total time was spent in fast swimming) (Table 4). However, the relative importance of these different swimming states varied with temperature. Indeed, the mean of residence time and the total periods allocated to breaks decreased with high temperature. Conversely, the relative importance of slow swimming activity increased with rising temperature, when considering both the mean residence time and the total time spent for this activity. This pattern was true for all experiments and for both sexes but was particularly marked for the summer populations. 
Table 3. Temora longicornis. Values of Shannon entropy $H$ (mean \pm confidence limits) estimated for experiments at ca. $13^{\circ} \mathrm{C}$ (1), $16^{\circ} \mathrm{C} \mathrm{(2),} 20^{\circ} \mathrm{C}(3)$ and $24^{\circ} \mathrm{C}(4)$ on 31 August 2007 (summer) and 26 February 2008 (winter). Significance differences ( ${ }^{*}$ ) during summer and winter for females, and winter for males (Mann-Whitney $U$-test, $\alpha=5 \%$ )

\begin{tabular}{|c|c|c|c|c|c|c|c|c|}
\hline & 1 & 2 & 3 & 4 & 1 & 2 & 3 & 4 \\
\hline Summer & $0.57 \pm 0.003^{*}$ & $0.58 \pm 0.01$ & $0.60 \pm 0.005$ & $0.62 \pm 0.01^{*}$ & $0.56 \pm 0.01$ & $0.57 \pm 0.006$ & $0.58 \pm 0.01$ & $0.58 \pm 0.01$ \\
\hline Winter & $0.56 \pm 0.007^{*}$ & $0.58 \pm 0.005$ & $0.61 \pm 0.02$ & $0.61 \pm 0.02^{*}$ & $0.56 \pm 0.008^{*}$ & $0.59 \pm 0.009$ & $0.61 \pm 0.006$ & $0.62 \pm 0.008^{*}$ \\
\hline
\end{tabular}

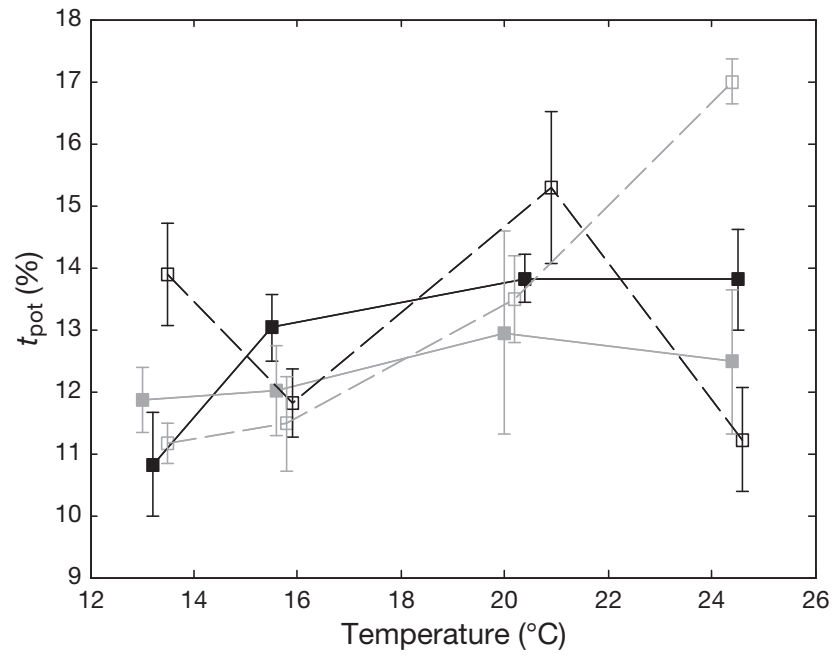

Fig. 5. Temora longicornis. Total time (mean \pm confidence limits) spent in potential sink $\left(t_{\mathrm{pot}}\right)$ calculated and averaged from trajectories extracted for each experiment at each temperature for males (black line) and females (grey line), for both experiments: 31 August 2007 (dotted line) and 26 February 2008 (solid line)

The total time allocated to slow swimming was 1.5 times higher in the warmest conditions compared with the coldest conditions for the summer population. Similarly, as temperature increased, the mean residence time in this activity was multiplied by 1.5 and 2 for females and males, respectively. The effect of temperature on the total time spent in fast swimming was particularly noticeable during the summer. Indeed, this measured time was multiplied by 33 and 25 for females and males, respectively, during this period. The magnitude of this increase was mainly due to very low values in cold conditions $(0.03 \%)$ and high values at $24^{\circ} \mathrm{C}(1 \%$ for females and $0.74 \%$ for males).

\section{DISCUSSION}

For all tested conditions, Temora longicornis spent nearly $100 \%$ of its time slowly cruising or 'hanging' stationary in the water column while moving its feeding appendages. This is in accordance with previous investigations (Tiselius \& Jonsson 1990, van Duren \& Videler 1995). In the present study, we showed that temperature significantly affected the behaviour of this species in both seasons and for both sexes. The copepods exhibited a reduction in both swimming speed and activity with decreasing temperature and an increase in both as temperatures rose. The behavioural complexity (as indicated by high $H$ values) was also enhanced at high temperatures, with a clear intermittence in the swimming activity and high variability. The extremes in swimming speed highlighted by probability density functions and longer time spent in cruise and jump behaviour indicated that this species follows a complex stochastic motion. The copepods exhibited high activity, revealed by the relative importance of slow and fast swimming occurring with a temperature rise.

Gerritsen (1982) found that the activity of Daphnia spp., measured as the frequency of upward or downward swimming excursions, was not only dependent on temperature, but also on temperature change, enhancing the diel vertical migration of zooplankton populations. However, in our study, before video recording began, the environmental temperature was changed gradually and slowly to the desired value and copepods were kept under constant temperature in dark conditions for around $1 \mathrm{~d}$, as well as during all the behavioural experiments. Thus, we assume that individuals were well acclimatized and the swimming response was not a consequence of temperature change and was even less of a display of the vertical migration mechanism (Calaban \& Makarewicz 1982, Cooke et al. 2008). Moreover, for the same reason, the motility change that occurred at the extreme temperature was neither a reflection of an avoidance response nor a stress response to stress-inducing temperature changes (Hakimzadeh \& Bradley 1990, Calaban \& Makarewicz 1982) 
Table 4. Temora longicornis. Main results of symbolic dynamic analysis: Values (mean \pm confidence limits) of residence time $(t)$ and proportion of time (PT) spent in each state: break (B), slow swimming (S) and fast swimming (F), at ca. $13^{\circ} \mathrm{C}\left(\mathrm{W} \_1, \mathrm{~S} \_1\right), 16^{\circ} \mathrm{C}\left(\mathrm{W} \_2\right.$, S_2), $20^{\circ} \mathrm{C}$ (W_3, S_3) and $24^{\circ} \mathrm{C}\left(\mathrm{W} \_4, \mathrm{~S} \_4\right)$ on 31 August 2007 (summer, S_1 to S_4) and 26 February 2008 (winter, W_1 to W_4). Significant differences between temperature conditions for the same sex and season $\left({ }^{*}\right)$, between both seasons for the same sex and temperature $\left({ }^{\Delta}\right)$ and between both sexes for the same temperature and season $\left({ }^{\diamond}\right)$ (Mann-Whitney $U$-test, $\alpha=5 \%$ )

\begin{tabular}{|c|c|c|c|c|c|c|}
\hline & $t_{\mathrm{B}}(\mathrm{s})$ & $\mathrm{PT}_{\mathrm{B}}(\%)$ & $t_{\mathrm{S}}(\mathrm{s})$ & $\mathrm{PT}_{\mathrm{S}}(\%)$ & $t_{\mathrm{F}}(\mathrm{s})$ & $\mathrm{PT}_{\mathrm{F}}(\%)$ \\
\hline \multicolumn{7}{|c|}{ Females } \\
\hline S_1 & $0.16 \pm 0.01$ & $68 \pm 1^{*}$ & $0.06 \pm 0.001$ & $31 \pm 1^{*}$ & $0.05 \pm 0.001$ & $0.7 \pm 0.2$ \\
\hline S_2 & $0.15 \pm 0.004$ & $67 \pm 1$ & $0.07 \pm 0.001$ & $33 \pm 1$ & $0.05 \pm 0.002$ & $0.3 \pm 0.1^{\Delta}$ \\
\hline S_3 & $0.11 \pm 0.01$ & $59 \pm 3^{* \Delta \diamond}$ & $0.07 \pm 0.006$ & $41 \pm 3^{* \Delta \diamond}$ & $0.07 \pm 0.01$ & $0.03 \pm 0.04^{*}$ \\
\hline S_4 & $0.1 \pm 0.03$ & $50 \pm 2^{* \Delta \diamond}$ & $0.1 \pm 0.002$ & $48 \pm 1^{* \Delta}$ & $0.1 \pm 0.001$ & $2 \pm 0.1^{* \Delta \diamond}$ \\
\hline \multicolumn{7}{|c|}{ Males } \\
\hline S_1 & $0.17 \pm 0.01$ & $71 \pm 2^{* \Delta}$ & $0.07 \pm 0.002$ & $29 \pm 2^{* \Delta}$ & $0.09 \pm 0.01$ & $0.1 \pm 0.1$ \\
\hline S_2 & $0.15 \pm 0.009$ & $67 \pm 2^{\Delta}$ & $0.07 \pm 0.002$ & $33 \pm 2^{\Delta}$ & $0.05 \pm 0.002$ & $0.05 \pm 0.02^{\Delta}$ \\
\hline S_3 & $0.1 \pm 0.003$ & $66 \pm 1^{\Delta \diamond}$ & $0.07 \pm 0.001$ & $34 \pm 1^{\Delta}$ & $0.04 \pm 0.001$ & $0.06 \pm 0.02^{\Delta}$ \\
\hline S_4 & $0.1 \pm 0.006$ & $52 \pm 1^{* \Delta \triangleleft}$ & $0.14 \pm 0.006$ & $48 \pm 1^{* \Delta}$ & $0.04 \pm 0.001$ & $0.2 \pm 0.005^{* \diamond}$ \\
\hline \multicolumn{7}{|c|}{ Females } \\
\hline W_1 & $0.15 \pm 0.007$ & $69 \pm 1$ & $0.07 \pm 0.001$ & $31 \pm 1$ & $0.05 \pm 0.003$ & $0.2 \pm 0.05^{* \diamond}$ \\
\hline W_2 & $0.15 \pm 0.007$ & $68 \pm 1$ & $0.07 \pm 0.001$ & $32 \pm 1$ & $0.05 \pm 0.003$ & $0.02 \pm 0.01^{\Delta \triangleleft}$ \\
\hline W_3 & $0.15 \pm 0.02$ & $67 \pm 2^{\Delta \diamond}$ & $0.07 \pm 0.004$ & $33 \pm 2^{\Delta \diamond}$ & $0.04 \pm 0.003$ & $0.09 \pm 0.05$ \\
\hline W_4 & $0.13 \pm 0.02$ & $62 \pm 3^{* \Delta}$ & $0.07 \pm 0.01$ & $37 \pm 3^{* \Delta}$ & $0.06 \pm 0.01$ & $0.6 \pm 0.1^{* \Delta}$ \\
\hline \multicolumn{7}{|c|}{ Males } \\
\hline W_1 & $0.16 \pm 0.01$ & $70 \pm 1^{* \Delta}$ & $0.07 \pm 0.002$ & $30 \pm 1^{* \Delta}$ & $0.04 \pm 0.003$ & $0.03 \pm 0.04^{* \diamond}$ \\
\hline W_2 & $0.15 \pm 0.007$ & $69 \pm 1^{* \Delta}$ & $0.06 \pm 0.0011$ & $31 \pm 1^{* \Delta}$ & $0.05 \pm 0.002$ & $0.2 \pm 0.08^{\Delta \triangleleft}$ \\
\hline W_3 & $0.14 \pm 0.003$ & $63 \pm 2^{\Delta \diamond}$ & $0.08 \pm 0.001$ & $37 \pm 1^{\Delta \diamond}$ & $0.05 \pm 0.001$ & $0.2 \pm 0.03^{\Delta}$ \\
\hline W_4 & $0.14 \pm 0.006$ & $63 \pm 1^{\Delta}$ & $0.08 \pm 0.002$ & $37 \pm 1^{\Delta}$ & $0.05 \pm 0.002$ & $0.2 \pm 0.03$ \\
\hline
\end{tabular}

which would have involved an increase in the energy required to move the swimming appendages or a mechanical hindrance of the appendages. In fact, copepods swim by vibrating the feeding appendages, and escape jumps are driven by repeated striking of their swimming legs (Strickler 1975). Moreover, copepods, through the mechanical displacement of mechanoreceptory setae on their antennules (which generate a neural signal), are sensitive to hydrodynamic signals generated by predators, prey or conspecifics (Gill \& Crisp 1985, Gill 1986). It is plausible that in a strong viscous environment (i.e. during winter), this mechanism may be less efficient and lead to a lesser sensitivity to disturbances and thus a more limited swimming activity (Lenz et al. 2005).

\section{Effect of environmental temperature on swimming behaviour}

\section{Mechanical constraints}

The viscosity of seawater is directly controlled by environmental temperature: the dynamic viscosity varies between 1.27 and $0.96 \times 10^{-3} \mathrm{~kg} \mathrm{~m}^{-1}$ $\mathrm{s}^{-1}$ for temperatures ranging from 13 to $25^{\circ} \mathrm{C}$. In addition, micro-organisms such as copepods swim under low Reynolds number conditions, thus viscosity effects dominate. It is therefore difficult to differentiate between the direct effect of temperature and the indirect effect of viscosity on the swimming activity of Temora longicornis. However, previous results have indicated environmental changes in viscosity associated with temperature can influence the small-scale processes of marine zooplanktonic organisms (Podolsky \& Emlet 1993, Bolton \& Havenhand 1997), even in free-swimming copepods (Larsen et al. 2008). Thus, the observed decrease in swimming velocity could have been the result of an adaptation to increased viscosity,

\section{Ecophysiological aspect: direct effect}

The most commonly used method to assess the energy requirements of organisms is to measure their rate of oxygen uptake, which is a function of temperature. Respiration rates are known to be higher in cold seasons than in warm seasons for several copepod species (Gaudy 1973). Furthermore, metabolic performance is sensitive to environmental conditions (Clarke 1991, Johnston et al. 1991, Hawkins 1995, Johnston et al. 1998). Thus, adaptation to a cold environment involves additional energy costs and may explain observed decrease of the potential of some biological processes such as reproduction (Devreker et al. 2005), as well as the observed decrease of the swimming effort.

\section{Ecological consequences}

The consequences of life in a cold environment (i.e. high energetic cost, low movement efficiency and limited mechano-sensitivity), have important 
implications in the ecology of copepods, as they are more vulnerable to predators and have a decreased ability to detect and catch potential sexual partners or prey. The ingestion rates of Temora longicornis are positively related to temperature (Dam \& Peterson 1988) and can be explained by the alteration of the allocated time for feeding movements in suspensionfeeding copepods (Cowles \& Strickler 1983, Price \& Paffenhöfer 1986). Moreover, although T. longicornis uses chemical signals to remotely locate mates, hydromechanical stimuli may be involved during the final phase of chasing the mate (Doall et al. 1998). The processes associated with reproduction can be disturbed by increasing viscosity. By reducing their ability to accomplish biological processes, lower temperatures may reduce the fitness of the species (Kramer et al. 2011). Consequently, the lower temperature condition could significantly exert selective pressures governing T. longicornis behaviour.

\section{Effects of extreme temperature}

Environmental factors such as temperature must satisfy minimum and maximum criteria to sustain organism or ecological processes. The maximal criteria represent the level at which factors exert constraints on organism productivity and thereby prevent them from achieving their full biological potential which could be realized under optimal conditions. In this sense, maximal criteria can involve toxicity or other biological damages and constitute a type of ecological stress. In the experiments at $24^{\circ} \mathrm{C}$, the copepods still showed an increase in swimming speed and activity, especially cruise, indicating an absence of stress and no adverse effect on behaviour. The unfavourable upper-level temperature may not be reached (Schmidt-Nielsen 1997). This demonstrates the ability to cope with changes in temperature by adjusting their swimming behaviour, as well as a tolerance to extremely high environmental temperatures. Previous studies on the metabolism and biological processes of this species have shown a tolerance to a wide range of temperature fluctuations (Peterson \& Kimmerer 1994, Devreker et al. 2005). In fact, reproduction of Temora longicornis takes place from 2.5 to $20^{\circ} \mathrm{C}$, with maximum fertility reached at ca. $18^{\circ} \mathrm{C}$ (Halsband \& Hirche 2001, Halsband-Lenk et al. 2002). The eurythermal nature of this species may explain its extended distribution area on both sides of the North Atlantic Ocean (CPR Survey Team 2004). In our study, there were no significant differences in behaviour between the sexes at temperatures similar to those found in the eastern English Channel (i.e. from 13 to $20^{\circ} \mathrm{C}$ ). This result was consistent with the work of Gill \& Crisp (1985) who observed similar appendage beat frequencies between $T$. longicornis males and females. Examination of spectra and symbolic analysis at extreme temperatures, however, revealed a greater responsiveness by females than males, as shown by the slopes of energy spectrum regression at $24^{\circ} \mathrm{C}$. Moreover, the maximum swimming speed of females was greater. This observation may reflect a lower resistance of males to extreme temperatures. Similar results have been found in other copepod species; for example, males of Eurytemora affinis are less tolerant to temperature changes than are females (Bradley 1978). Compared with females, male Eucyclops agilis also show a significant reduction in swimming activity at high temperatures $\left(15\right.$ to $\left.20^{\circ} \mathrm{C}\right)$, which coincides with a marked increase in their respiration rate (LaybournParry \& Tinson 1985). Devreker et al. (2005) showed that an increase in temperature has a negative effect on the survival of $T$. longicornis in the eastern English Channel, probably because of a rise in the energy cost of metabolism. A decrease in activity in males at $24^{\circ} \mathrm{C}$ could have been the result of an adaptation to high temperatures, involving a rise in energy requirements.

\section{Interseasonal variability}

\section{Seasonal effect}

The succession of generations for Temora longicornis has been shown by Halsband-Lenk et al. (2004): life history traits, including functional responses, e.g. respiration, vary through generations and seasons (Berner 1962). In fact, the ability to resist changes in temperature may depend on the environmental temperature conditions in which the copepods develop and mature. Generally, marine copepod species which have a maximum biomass during spring and autumn have a lethal temperature lower than that of those with a maximum biomass in summer (Deevey 1960, Gaudy \& Thibault-Botha 2007). During our experiment, the winter population showed a relatively greater swimming speed at the lowest temperature and less activity at the warmest condition. Similarly, Elphick \& Shine (1998) were able to show that lizards Bassiana duperreyi acclimatized to warm temperatures could maintain a higher running speed at warmer temperatures than lizards that were not acclimatized to warm conditions. However, the 
behaviour of copepods is influenced not only by temperature, but also by factors such as prey availability and physiological state. Copepods spend less time in the 'slow swimming' and more time in the 'break' state when food concentrations decrease (Cowles \& Strickler 1983). The higher activity observed in the high temperature experiment in the summer population may have been the result of a better nutrition and physiological state compared with the winter population. In conclusion, these differences between the populations appear to depend on the food quantity and quality and/or on adaptations to the prevailing temperatures of the habitat.

\section{Ecological implications}

Temora longicornis is known as a species with a high metabolic rate, but low energy reserves with limited lipid accumulation (Fraser et al. 1989, Helland et al. 2003, Kreibich et al. 2008). Therefore, survival and reproductive success are directly dependent on food availability and feeding behaviour (Koski \& Klein Breteler 2003). Both phytoplankton (Breton et al. 2000, Gómez \& Souissi 2008) and T. longicornis biomass (John et al. 2001) are low during the winter in the eastern English Channel. Time spent cruising (e.g. slow swimming) was greater in the winter population than in the summer one. This strategy may allow the species to increase the potential encounter rate and thus ensure feeding and mating processes in ecosystems that present lower food and partner availability during winter. In fact, $T$. longicornis breed continuously throughout the year, even in winter (Halsband-Lenk et al. 2004). In addition to production of resting eggs (Lindley 1986, 1990), the egg production in winter keeps a stock of premature stages ready to use the algal spring bloom and may contribute to a rapid recruitment in early spring (Le Ruyet-Person et al. 1975).

The most abundant copepods in the English Channel are the genera Pseudocalanus, Temora, Calanus, Centropages and Acartia (Quisthoudt et al. 1987, John et al. 2001). Generally, the maximum numbers of copepods are recorded at the end of May, and copepod stocks remain hight throughout the summer (Quisthoudt et al. 1987, Mauchline 1998, John et al. 2001). These species have similar sizes and feeding modes, being filter-feeders (e.g. Temora, Pseudocalanus) or intermittent filter-feeders depending on prey size (e.g. Acartia, Calanus, Centropages) (Jonsson \& Tiselius 1990, Hansen et al. 1994). They may have the same kind of microplanktonic prey. Phyto- plankton biomass also has a seasonal pattern with a bloom in early spring and a quick decrease until summer, after which a stable smaller biomass remains for the remainder of the season (Gentilhomme \& Lizon 1998). Thus, interspecific and intraspecific competition becomes more important during summer as a result of the reduction in the prey: predator ratio. The most visible result of the present study was the difference between the 2 populations at the warmest temperature: mean and maximum swimming speeds were significantly higher for the summer population. The ability of Temora longicornis to maintain high swimming speeds could allow it to increase its exploration area, and thus remain competitive with respect to its foraging behaviour.

Pelagic copepods with a marked seasonality are challenged with maintaining an effective behavioural performance to carry out essential functions, such as reproduction and feeding, while facing a decline in metabolic rate due to the temperature decrease. This capacity of pelagic copepods could partly explain the population dynamics pattern of Temora longicornis in the English Channel in which individuals and egg production continue throughout the year, ensuring a successful survival of the overwintering population.

This contribution to the understanding of Temora longicornis behaviour and ecology allows us to interpret the life history strategy of this calanoid copepod in English Channel ecosystem. Our results highlight the importance of considering seasonal temperature trends when assessing its potential effects on key biological processes. However, to achieve a complete overview of the effect of temperature, it is necessary to take the different space-time scales into account, in particular the scale on a daily basis. Indeed, zooplanktonic organisms tolerate a specific range of temperatures depending on their recent thermal history (Calaban \& Makarewicz 1982, Voznesensky et al. 2004). In addition, zooplankton exposed to weak temperature gradients on a daily cycle exhibit adaptive responses through synchronization of vertical migration processes (Gerritsen 1982). Therefore, a continuation of this work would be to consider the impact of the daily temperature cycle on the seasonal adaptive behaviour of $T$. longicornis.

Acknowledgements. A fellowship provided by Deutscher Akademischer Austauschdienst (DAAD) is gratefully acknowledged. Advice and comments supplied by Dr. J. C. Molinero are thankfully acknowledged. The authors also thank P. Magee for his quality English editing (www. englisheditor.webs.com). 


\section{LITERATURE CITED}

Beaugrand G, Reid PC, Ibañez F, Lindley JA, Edwards M (2002) Reorganization of North Atlantic marine copepod biodiversity and climate. Science 296:1692-1694

Berner A (1962) Feeding and respiration in the copepod Temora longicornis (Müller). J Mar Biol Assoc UK 42: 625-640

$>$ Bolton TF, Havenhand JN (1997) Physiological versus viscosity-induced effects of water temperature on the swimming and sinking velocity of larvae of the serpulid polychaete Galeolaria caespitose. Mar Ecol Prog Ser 159: 209-218

Bradley BP (1978) Increase in range of temperature tolerance by acclimation in the copepod Eurytemora affinis. Biol Bull (Woods Hole) 154:177-187

> Breton E, Brunet C, Sautour B, Brylinski JM (2000) Annual variations of phytoplankton biomass in the eastern English Channel: comparison by pigment signatures and microscopic counts. J Plankton Res 22:1423-1440

Brown JH, Gillooly JF, Allen AP, Savage VM, West GB (2004) Toward a metabolic theory of ecology. Ecology 85: 1771-1789

Brylinski JM, Bentley D, Quisthoudt C (1988) Discontinuité écologique et zooplancton (copépodes) en Manche orientale. J Plankton Res 10:503-513

Calaban MJ, Makarewicz JC (1982) The effect of temperature and density on the amplitude of vertical migration of Daphnia magna. Limnol Oceanogr 27:262-271

> Clark RA, Fox CJ, Viner D, Livermore M (2003) North Sea cod and climate change-modelling the effects of temperature on population dynamics. Glob Change Biol 9: 1669-1680

Clarke A (1991) What is cold adaptation and how should we measure it? Am Zool 31:81-92

> Cooke SL, Williamson CE, Leech DM, Boeing WJ, Torres L (2008) Effect of temperature and ultraviolet radiation on diel vertical migration of freshwater crustacean zooplankton. Can J Fish Aquat Sci 65:1144-1152

Cowles TJ, Strickler JR (1983) Characterization of feeding activity patterns in the planktonic copepod Centropages typicus Kroyer under various food conditions. Limnol Oceanogr 28:106-115

CPR (Continuous Plankton Recorder) Survey Team (2004) Continuous plankton records: plankton atlas of the North Atlantic Ocean (1958-1999). II. Biogeographical charts. Mar Ecol Prog Ser Suppl 2004:11-75

> Dam HG, Peterson WT (1988) The effect of temperature on the gut clearance rate constant of planktonic copepods. J Exp Mar Biol Ecol 123:1-14

Deevey G (1960) The zooplankton of the surface waters of the Delaware Bay region. Bull Bingham Oceanogr Collect 17:5-53

Devreker D, Souissi S, Seuront L (2005) Effects of chlorophyll concentration and temperature variation on the reproduction and survival of Temora longicornis (Copepoda, Calanoida) in the Eastern English Channel. J Exp Mar Biol Ecol 318:145-162

Doall MH, Colin SP, Yen J, Strickler JR (1998) Locating a mate in 3D: the case of Temora longicornis. Philos Trans R Soc Lond B Biol Sci 353:681-687

Dur G, Schmitt FG, Souissi S (2007) Analysis of high frequency temperature time series in the Seine estuary from the Marel autonomous monitoring buoy. Hydrobiologia 588:59-68
Dur G, Souissi S, Schmitt F, Cheng SH, Hwang JS (2010) The different aspects in motion of the three reproductive stages of Pseudodiaptomus annandalei (Copepoda, Calanoida). J Plankton Res 32:423-440

- Ebeling W (1997) Prediction and entropy of nonlinear dynamical systems and symbolic sequences with LRO. Physica D 109:42-52

- Elphick MJ, Shine R (1998) Long term effects of incubation temperatures on the morphology and locomotor performance of hatchling lizards (Bassiana duperreyi, Scincidae). Biol J Linn Soc 63:429-447

> Fraser AJ, Sargent JR, Gamble JC (1989) Lipid class and fatty acid composition of Calanus finmarchicus (Gunnerus), Pseudocalanus sp., and Temora longicornis Müller from a nutrient-enriched seawater enclosure. J Exp Mar Biol Ecol 130:81-92

Frederiksen M, Edwards M, Richardson AJ, Halliday NC, Wanless S (2006) From plankton to top predators: bottom-up control of a marine food web across four trophic levels. J Anim Ecol 75:1259-1268

Gaudy R (1973) Les variations saisonieres de la respiration chez quatre especes de copepods pelagiques de Golfe de Marseille. Neth J Sea Res 7:267-279

Gaudy R, Thibault-Botha D (2007) Metabolism of Centropages species in the Mediterranean Sea and the North Atlantic Ocean. Prog Oceanogr 72:151-163

Gauld DT, Raymont JEG (1953) The respiration of some planktonic copepods. II. The effect of temperature. J Mar Biol Assoc UK 31:447-460

Gentilhomme V, Lizon F (1998) Seasonal cycle of nitrogen and phytoplankton biomass in a well-mixed coastal system (Eastern English Channel). Hydrobiologia 361: 191-199

Gerritsen J (1982) Behavioral response of Daphnia to rate of temperature change: possible enhancement of vertical migration. Limnol Oceanogr 27:254-261

Gill CW (1986) Suspected mechano- and chemosensory structures of Temora longicornis (Copepoda: Calanoida). Mar Biol 93:449-457

Gill CW, Crisp DJ (1985) The effect of size and temperature on the frequency of limb beat of Temora longicornis Müller (Crustacea: Copepoda). J Exp Mar Biol Ecol 86: 185-196

Goetze E, Kiørboe T (2008) Heterospecific mating and species recognition in the planktonic marine copepods Temora stylifera and T. longicornis. Mar Ecol Prog Ser 370:185-198

Gómez F, Souissi S (2008) The impact of the 2003 summer heat wave and the 2005 late cold wave on the phytoplankton in the north-eastern English Channel. C R Biol 331:678-685

Granata TC, Dickey TD (1991) The fluid mechanics of copepod feeding in a turbulent flow: a theoretical approach. Prog Oceanogr 26:243-261

Hakimzadeh R, Bradley BP (1990) The heat shock response in the copepod Eurytemora affinis (Poppe). J Therm Biol 15:67-77

> Halsband C, Hirche HJ (2001) Reproductive cycles of dominant calanoid copepods in the North Sea. Mar Ecol Prog Ser 209:219-229

> Halsband-Lenk C, Hirche HJ, Carlotti F (2002) Temperature impact on reproduction and development of congener copepod populations. J Exp Mar Biol Ecol 271:121-153

Halsband-Lenk C, Carlotti F, Greve W (2004) Life-history strategies of calanoid congeners under two different 
climate regimes: a comparison. ICES J Mar Sci 61: 709-720

> Hansen B, Bjørnsen PK, Hansen PJ (1994) The size ratio between planktonic predators and their prey. Limnol Oceanogr 39:395-403

Hawkins AJS (1995) Effects of temperature change on ectotherm metabolism and evolution: metabolic and physiological interrelations underlying the superiority of multilocus heterozygotes in heterogeneous environments. J Therm Biol 20:23-33

Head EJH, Wang R, Conover RJ (1984) Comparison of diurnal feeding rhythms in Temora longicornis and Centropages hamatus with digestive enzyme activity. J Plankton Res 6:543-551

$>$ Helland S, Terjesen BF, Berg L (2003) Free amino acid and protein content in the planktonic copepod Temora longicornis compared to Artemia franciscana. Aquaculture 215:213-228

Hirche HJ (1987) Temperature and plankton. II. Effect on respiration and swimming activity in copepods from the Greenland Sea. Mar Biol 94:347-356

> Holste L, St. John MA, Peck MA (2009) The effects of temperature and salinity on reproductive success of Temora longicornis in the Baltic Sea: a copepod coping with a tough situation. Mar Biol 156:527-540

Ikeda T, Kanno Y, Ozaki K, Shinada A (2001) Metabolic rates of pelagic marine copepods as a function of body mass and temperature. Mar Biol 139:587-596

John EH, Batten SD, Harris RP, Hays GC (2001) Comparison between zooplankton data collected by the Continuous Plankton Recorder survey in the English Channel and by WP-2 nets at station L4, Plymouth (UK). J Sea Res 46: 223-232

> Johnston IA, Clarke A, Ward P (1991) Temperature and metabolic rate in sedentary fish from the Antarctic, North Sea and Indo-West Pacific Ocean. Mar Biol 109:191-195

> Johnston IA, Calvo J, Guderley H, Fernandez D, Palmer L (1998) Latitudinal variation in the abundance and oxidative capacities of muscle mitochondria in perciform fishes. J Exp Biol 201:1-12

> Jonsson P, Tiselius P (1990) Feeding behavior, prey detection and capture efficiency of the copepod Acartia tonsa feeding on planktonic ciliates. Mar Ecol Prog Ser 60: $35-44$

Kinne O (1970) Temperature: animals - invertebrates. In: Kinne O (ed) Marine ecology, Vol 1, environmental factors, Part 1. Wiley-Interscience, London, p 407-514

Koski M, Klein Breteler WCM (2003) Influence of diet on copepod survival in the laboratory. Mar Ecol Prog Ser 264:73-82

- Kramer AM, Sar nelle O, Yen J (2011) The effect of mating beh avior and temperature variation on the critical population density of a freshwater copepod. Limnol Oceanogr 56:707-715

> Kreibich T, Saborowski R, Hagen W, Niehoff B (2008) Shortterm variation of nutritive and metabolic parameters in Temora longicornis females (Crustacea, Copepoda) as a response to diet shift and starvation. Helgol Mar Res 62: 241-249

> Larsen PS, Madsen CV, Riisgård HU (2008) Effect of temperature and viscosity on swimming velocity of the copepod Acartia tonsa, brine shrimp Artemia salina and rotifer Brachionus plicatilis. Aquat Biol 4:47-54

Laybourn-Parry J, Tinson S (1985) Respiratory studies on two benthic copepods Acanthocyclops viridis and Eucy- clops agilis at environmental temperatures. Oecologia 65:566-572

Le Ruyet-Person J, Razouls C, Razouls S (1975) Biologie comparée entre espèces vicariantes et communes de copépodes dans un écosystème néritique en Méditerranée et en Manche. Vie Milieu 25:283-312

Lenz PH, Hower AE, Hartline DK (2005) Temperature compensation in the escape response of a marine copepod, Calanus finmarchicus (Crustacea). Biol Bull (Woods Hole) 209:75-85

Levitus S, Antonov JI, Boyer TP, Stephens C (2000) Warming of the world ocean. Science 287:2225-2229

> Levitus S, Antonov J, Boyer T (2005) Warming of the world ocean, 1955-2003. Geophys Res Lett 32:L02604 doi: 10.1029/2004GL021592

Lindley JA (1986) Dormant eggs of calanoid copepods in sea-bed sediments of the English Channel and southern North Sea. J Plankton Res 8:399-400

Lindley JA (1990) Distribution of overwintering calanoid copepod eggs in sea-bed sediments around southern Britain. Mar Biol 104:209-217

> Mangum CP, Oakcs MJ, Shick JM (1972) Rate-temperature responses in scyphozoan medusae and polyps. Mar Biol 15:298-303

Mauchline J (1998) The biology of calanoid copepods. Advances in marine biology, Vol 33. Academic Press, New York, NY

> Michalec FG, Souissi S, Dur G, Mahjoub MS, Schmitt FG, Hwang JS (2010) Differences in behavioral responses of Eurytemora affinis (Copepoda, Calanoida) reproductive stages to salinity variations. J Plankton Res 32:805-813

> Moison M, Schmitt FG, Souissi S, Seuront L, Hwang JS (2009) Symbolic dynamics and entropies of copepod behaviour under non-turbulent and turbulent conditions. J Mar Syst 77:388-396

Molinero JC, Ibanez I, Souissi S, Buecher E, Dallot S, Nival $\mathrm{P}$ (2008) Climate control on the long-term anomalous changes of zooplankton communities in the northwestern Mediterranean. Glob Change Biol 14:11-26

> Peterson WT, Kimmerer WJ (1994) Processes controlling recruitment of the marine calanoid copepod Temora longicornis in Long Island Sound: egg production, egg mortality, and cohort survival rates. Limnol Oceanogr 39: 1594-1605

Podolsky RD, Emlet RB (1993) Separating the effects of temperature and viscosity on swimming and water movement by sand dollar larvae (Dendraster excentricus). J Exp Biol 176:207-222

Pörtner HO, Farrell AP (2008) Physiology and climate change. Science 322:690-692

Price HJ, Paffenhöfer GA (1986) Effects of concentration on the feeding of a marine copepod in algal monocultures and mixtures. J Plankton Res 8:119-128

Quisthoudt C, Bentley D, Brylinski JM (1987) Discontinuité hydrobiologique dans le détroit du Pas-de-Calais. J Plankton Res 9:995-1002

Richardson AJ, Schoeman DS (2004) Climate impact on plankton ecosystems in the Northeast Atlantic. Science 305:1609-1612

Schmidt-Nielsen K (1997) Animal physiology-adaptations and environment, 5th edn. Cambridge University Press, Cambridge

Schmitt F, Seuront L (2001) Multifractal random walk in copepod behavior. Physica A 301:375-396

Schmitt FG, Seuront L, Hwang JS, Souissi S, Tseng LC 
(2006) Scaling of swimming sequences in copepod behavior: data analysis and simulation. Physica A 364: 287-296

Strickler JR (1975) Swimming of planktonic Cyclops species (Copepoda, Crustacea): pattern, movements and their control. In: Wu TWT, Brokaw CJ, Brennen C (eds) Swimming and flying in nature. Plenum Press, Princeton, NJ, p 599-616

Tiselius P (1992) Behavior of Acartia tonsa in patchy food environments. Limnol Oceanogr 37:1640-1651

Tiselius P, Jonsson PR (1990) Foraging behaviour of six calanoid copepods: observations and hydrodynamic analysis. Mar Ecol Prog Ser 66:23-33

Tiselius P, Jonsson PR, Kaartvedt S, Olsen EM, Jørstad T (1997) Effects of copepod foraging behavior on predation risk: an experimental study of the predatory copepod Pareuchaeta norvegica feeding on Acartia clausi and A. tonsa (Copepoda). Limnol Oceanogr 42:164-170

van Duren LA, Videler JJ (1995) Swimming behaviour of

Editorial responsibility: J. Rudi Strickler,

Milwaukee, Wisconsin, USA developmental stages of the calanoid copepod Temora longicornis at different food concentrations. Mar Ecol Prog Ser 126:153-161

van Duren LA, Videler JJ (1996) The trade-off between feeding, mate seeking and predator-prey avoidance in copepods: behavioural responses to chemical cues. J Plankton Res 18:805-818

- Voznesensky M, Lenz PH, Spanings-Pierrot C, Towle DW (2004) Genomic approaches to detecting thermal stress in Calanus finmarchicus (Copepoda: Calanoida). J Exp Mar Biol Ecol 311:37-46

Weissburg MJ, Doall MH, Yen J (1998) Following the invisible trail: kinematic analysis of mate-tracking in the copepod Temora longicornis. Philos Trans R Soc Lond B Biol Sci 353:701-712

Williams R, Conway DVP, Hunt HG (1994) The role of copepods in the planktonic ecosystems of mixed and stratified waters of the European shelf seas. Hydrobiologia 292-293: $521-530$

Submitted: May 23, 2011; Accepted: April 11, 2012 Proofs received from author(s): July 20, 2012 